\title{
Effects of pneumoperitoneal pressure and position changes on respiratory mechanics during laparoscopic colectomy
}

\author{
Jin Suk Park, Eun Jin Ahn, Duk Dong Ko, Hyun Kang, Hwa Yong Shin, Chong Hwa Baek, Yong Hun Jung, \\ Young Cheol Woo, Jin Yun Kim, and Gill Hoi Koo
}

Department of Anesthesiology and Pain Medicine, College of Medicine, Chung-Ang University, Seoul, Korea

Background: This study was designed to assess the effects of pneumoperitoneal pressure (PP) and positional changes on the respiratory mechanics during laparoscopy assisted colectomy.

Methods: Peak inspiratory pressure, plateau pressure, lung compliance, and airway resistance were recorded in PP of $10 \mathrm{mmHg}$ and $15 \mathrm{mmHg}$, with the position change in 5 steps: head-down at $20^{\circ}$, head-down at $10^{\circ}$, neutral position, head-up at $10^{\circ}$ and head-up at $20^{\circ}$.

Results: When the patient was placed head-down, the position change accentuated the effects of pneumoperitoneum on respiratory mechanics. However, when the patient was placed in a head-up position during pneumoperitoneum the results showed no pattern. In the $20^{\circ}$ head-up position with the PP being $10 \mathrm{mmHg}$, the compliance increased from 30.6 to $32.6 \mathrm{ml} / \mathrm{cmH}_{2} \mathrm{O}$ compared with neutral position $(\mathrm{P}=0.002)$. However with the $\mathrm{PP}$ being $15 \mathrm{mmHg}$, the compliance had not changed compared with neutral position $(\mathrm{P}=0.989)$. In $20^{\circ}$ head-down position with the $\mathrm{PP}$ of 10 $\mathrm{mmHg}$, the compliance was measured as $24.2 \mathrm{ml} / \mathrm{cmH}_{2} \mathrm{O}$. This was higher than that for patients in the $10^{\circ}$ head-down position with a $\mathrm{PP}$ of $15 \mathrm{mmHg}$, which was recorded as $21.2 \mathrm{ml} / \mathrm{cmH}_{2} \mathrm{O}$. Also in the airway resistance, the patient in the $20^{\circ}$ head-down position with the PP of $10 \mathrm{mmHg}$ showed $15.8 \mathrm{cmH}_{2} \mathrm{O} / \mathrm{L} / \mathrm{sec}$, while the patient in the $10^{\circ}$ headdown position with the PP of $15 \mathrm{mmHg}$ showed $16.2 \mathrm{cmH}_{2} \mathrm{O} / \mathrm{L} / \mathrm{sec}$ of airway resistance. These results were not statistically significant but still suggested that the head-down position accentuated the effects of pneumoperitoneum on respiratory mechanics.

Conclusions: Our results suggest that respiratory mechanics are affected by the patient position and the level of PP the latter having greater effect. (Korean J Anesthesiol 2012; 63: 419-424)

Key Words: Laparocolectomy, Pneumoperitoneum, Position, Respiratory mechanics.

Received: November 11, 2011. Revised: 1st, March 7, 2012; 2nd, May 9, 2012; 3rd, May 31, 2012. Accepted: June 8, 2012.

Corresponding author: Hyun Kang, M.D., Department of Anesthesiology and Pain Medicine, College of Medicine, Chung-Ang University, 224-1, Heukseok-1dong, Dongjak-gu, Seoul 156-756, Korea. Tel: 82-2-6299-2571, Fax: 82-2-6298-8351, E-mail: roman00@naver.com

(c) This is an open-access article distributed under the terms of the Creative Commons Attribution Non-Commercial License (http:// creativecommons.org/licenses/by-nc/3.0/), which permits unrestricted non-commercial use, distribution, and reproduction in any medium, provided the original work is properly cited. 


\section{Introduction}

Respiratory complications that develop in patients receiving major surgery can extend hospital stays and are an important factor that increases patient morbidity and mortality. Colon cancer has the third highest morbidity and mortality rates, trends that are increasing, and laparoscopic colectomy is performed more frequently than laparotomy as a surgical treatment [1]. However, laparoscopic colectomy is an abdominal surgery that takes many hours and there are risks of respiratory complications, such as pulmonary edema or atelectasis. Thus, in the perioperative period, careful management of the respiratory system is necessary.

There have been reports of laparoscopic colectomy being safely performed on patients in whom the procedure was relatively contraindicated in the past, such as patients who are American Society of Anesthesiologists (ASA) level 3 or 4, elderly patients who are 80 years or older, and obese patients $(30 \mathrm{~kg} /$ $\mathrm{m}^{2}$ or more): hence, the implications have broaden [2]. However, these patients have a higher possibility of developing respiratory complications compared to other patients, and the occurrence of complications is closely connected to respiratory mechanics and research regarding the changes in respiratory mechanics in intraoperative patients is essential [3].

In laparoscopy, there is the risk of pneumothorax, hypoxemia, hypercarbia, respiratory acidosis, and subcutaneous emphysema due to pneumoperitoneum, which develops from the insertion of carbon dioxide into the intraperitoneum during surgery [4]. In addition, the intraperitoneal pressure increases due to pneumoperitoneum, and this causes the diaphragm to move cephalad, leading to increased intrathoracic pressure and mean airway pressure as a result. The intraatrial pressure increases as intrathoracic pressure increases, and the resulting decrease in venous return reduces cardiac output [5]. Moreover, as carbon dioxide is absorbed in the blood, minute ventilation increases and mean airway pressure increases even more as a result. In this situation, a position change to head down or to the Trendelenburg during laparoscopic colectomy, which further influences the location change of the intestines and diaphragm to significantly reduce the lung volume [6]. Therefore, it is important to examine the changes in respiratory mechanics according to the patient's position during laparoscopy and the change in intraperitoneal pressure.

Though there have been many studies on laparoscopy, there had been no investigations regarding change in intraperitoneal pressure according to position. These are the only studies that researched the change in respiratory mechanics according to position change with fixed intraperitoneal pressure. When performing laparoscopic colectomy, the head down position and pneumoperitoneum state are maintained for more than 2 hours. So it was anticipated that the sustained pneumoperitoneum would affect the respiratory mechanics of the patient. Therefore, this study aimed to investigate the effect of patient position and change in intraperitoneal pressure on the respiratory mechanics of patients.

\section{Materials and Methods}

The researchers obtained approval from the hospital's Institutional Review Board as well as consent from the patients and guardians, after explaining the purpose and method of the research, before proceeding with the study. This research was performed on 30 adult male and female patients who were ASA level 1 or 2 and scheduled for laparoscopic colectomy. Patients with severe pulmonary disease, hypertension, diabetes mellitus, or sympathetic disorders were excluded from the study. The demographic information, pneumoperitoneum time, and operating time of the subjects are shown in Table 1.

Standard monitoring equipment was implemented and preoxygenation was performed for approximately $5 \mathrm{~min}$ via a facial mask. Then fentanyl $1 \mu \mathrm{g} / \mathrm{kg}$ was administered, and $1 \mathrm{~min}$ later loss of consciousness was induced with $5 \mathrm{mg} / \mathrm{kg}$ pentothal sodium. After verifying loss of consciousness with loss of eyelid reflex, $1 \mathrm{mg} / \mathrm{kg}$ succinylcholine was administered for muscle relaxation. Tracheal intubation was performed using a laryngoscope, and vecuronium $0.1 \mathrm{mg} / \mathrm{kg}$ was administered to maintain muscle relaxation. Anesthesia was maintained with sevoflurane 2 vol\%, $\mathrm{N}_{2} \mathrm{O} 1.5 \mathrm{~L} / \mathrm{min}$, and $\mathrm{O}_{2} 1.5 \mathrm{~L} / \mathrm{min}$, and the volume percentage of sevoflurane was adjusted according to hemodynamic changes. By measuring train of four during surgery, an additional dose of vecuronium $0.05 \mathrm{mg} / \mathrm{kg}$ was administered to maintain muscle relaxation when there was insufficient muscle relaxation. To check respiratory mechanics after inducing anesthesia, a spirometry module $\left(\mathrm{S} / 5^{\mathrm{TM}}\right.$ Compact Anesthesia Monitor; Datex-Ohmeda, Tewksbury, MA, USA) was attached to the tracheal tube to measure changes in respiratory mechanics.

Peak inspiratory pressure (Ppeak), Plateau pressure (Pplat), lung compliance (Comp), and airway resistance (Raw) were measured for respiratory mechanic changes. Measurements were taken directly after tracheal intubation and before

Table 1. Patient Demographics

\begin{tabular}{lc}
\hline Age $(\mathrm{yr})$ & $64.5 \pm 9.1$ \\
Sex $(\mathrm{M} / \mathrm{F})$ & $23 / 7$ \\
Weight $(\mathrm{kg})$ & $67.2 \pm 11.0$ \\
Height $(\mathrm{cm})$ & $164.1 \pm 6.9$ \\
Body mass index $\left(\mathrm{kg} / \mathrm{m}^{2}\right)$ & $24.5 \pm 3.1$ \\
Operation time $(\mathrm{min})$ & $222.5 \pm 43.5$ \\
$\mathrm{CO}_{2}$ insufflation time (min) & $201.1 \pm 43.1$ \\
\hline
\end{tabular}

Values are mean \pm SD or number of patients. 
inducing pneumoperitoneum in supine position (PI). Also, changes in respiratory mechanic were recorded, while maintaining intraperitoneal pressure at $10 \mathrm{mmHg}$ in head down $20^{\circ}$ (D20), head down $10^{\circ}$ (D10), supine (N), head up $10^{\circ}$ (U10), and head up $20^{\circ}$ (U20) positions. Then, intraperitoneal pressure was maintained at $15 \mathrm{mmHg}$, while measurements were taken in the same sequence as previous steps at $10 \mathrm{mmHg}$ intraperitoneal pressure. Whenever a position was changed, a goniometer was attached horizontally to the side of the bed to measure the degree of inclination. The surgery was begun after measuring all respiratory changes, and was performed in the head down $20^{\circ}$ with intraperitoneal pressure $15 \mathrm{mmHg}$. In addition, respiratory mechanical changes were measured in the horizontal position after terminating the pneumoperitoneum at the end of surgery (End). While measuring respiratory mechanics, the mean tidal volume was $10 \mathrm{ml} / \mathrm{kg}$ based on ideal body weight, and the respiratory rate was controlled so end tidal carbon dioxide concentration was maintained at $40 \pm 3 \mathrm{mmHg}$ in each patients. The ratio of inspiration to expiration was set to be $1: 2$. To minimalize the effect of respiratory system, ventilator settings were fixed during the investigation. Before measuring respiratory mechanics at each stage of intraperitoneal pressure and position change, approximately 3 minutes were given to allow the patient to reach equilibrium. Each respiratory mechanics variable was measured 3 times to obtain the mean value, and this was used as a single measurement.

A pilot study was performed in 10 patients undergoing laparoscopic colectomy to determine the required sample size of the

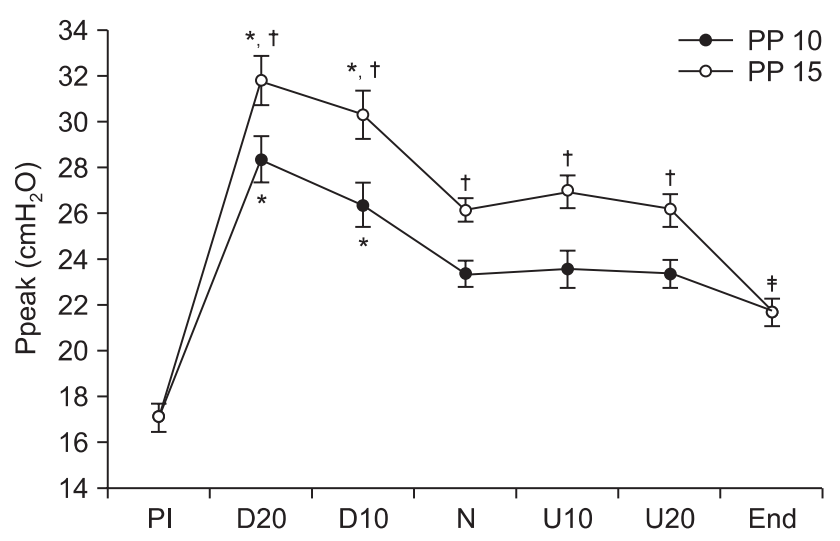

Fig. 1. These are changes of peak airway pressure (Ppeak) during laparoscopic assisted colectomy. Peak airway pressure (Ppeak) during head-down position (D20, D10) is higher than in the neutral position (N). All parameters at PP 15 are higher than PP 10. Ppeak after deflation of pneumoperitoneum (End) is higher than Ppeak before insufflation (PI). *PP 10: peritoneal pressure $10 \mathrm{mmHg}$, PP 15: peritoneal pressure $15 \mathrm{mmHg}$, D20: head-down $20^{\circ}$, D10: head-down $10^{\circ}$, U20: head-up $20^{\circ}$, U10: head-up $10^{\circ}$. Values are express as mean \pm SD. $\mathrm{P}<0.05$ compared with neutral position, ${ }^{\dagger} \mathrm{P}<0.05$ compared with PP $10,{ }^{\ddagger} \mathrm{P}<0.05$ compared with PI. research subjects, and the mean value obtained by measuring peak airway pressure through the pilot study was $26.7 \mathrm{cmH}_{2} \mathrm{O}$ with a standard deviation of 5.1. Under the hypothesis that primary autocorrelation shows autocorrelation, the autocorrelation coefficient of 0.7 was applied. To distinguish a $10 \%$ difference in peak airway pressure according to patient position and intraperitoneal pressure, calculation was carried out with $\alpha$ error as $5 \%$ and power as $\mathbf{8 0 \%}$. The result of the calculation showed that the number of subjects required was 30 . All measurements were expressed as mean \pm standard deviation. The comparison of respiratory mechanics variables at the start and end of surgery was performed with the paired t-test, the changes in respiratory mechanics variables obtained at each intraperitoneal pressure and position were analyzed with two-way repeated measures ANOVA, and a post-hoc test was performed using the Turkey test. All results were considered statistically significant when the P value was 0.05 or less.

\section{Results}

The research results showed that pneumoperitoneum increased Ppeak, Pplat, and Raw while reducing Comp. When intraperitoneal pressure was increased from $10 \mathrm{mmHg}$ to 15 mmHg in N, Ppeak increased $11.97 \%$, Pplat increased $12.38 \%$, Raw increased 5.46\%, and Comp decreased $11.11 \%$.

In all positions the Ppeak and Pplat were significantly higher when the intraperitoneal pressure was $15 \mathrm{mmHg}$ than when it was $10 \mathrm{mmHg}(\mathrm{P}<0.05)$. However, there were no

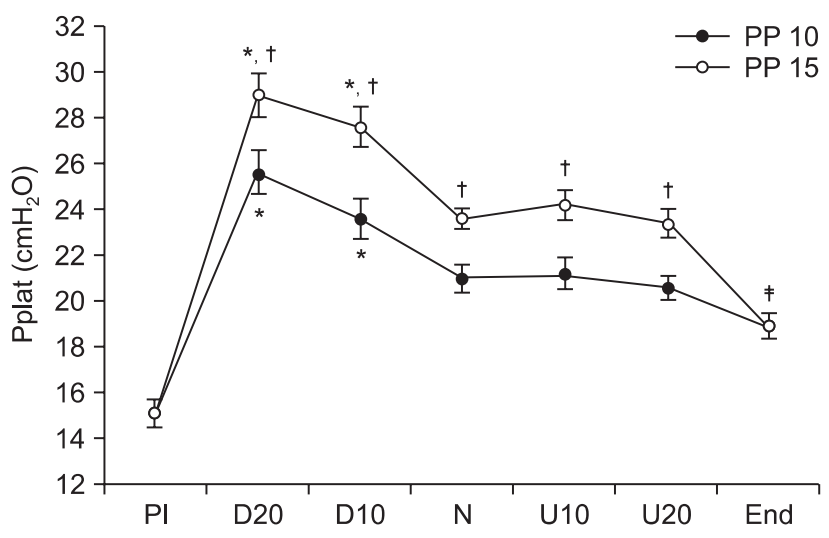

Fig. 2. These are changes of plateau pressure (Pplat) during laparoscopic assisted colectomy. Pplat during head-down position (D20, D10) is higher than in the neutral position. All parameters at PP 15 are higher than at PP 10. Plateau pressure after deflation of pneumoperitoneum (End) is higher than Pplat before insufflation (PI). PP 10: peritoneal pressure $10 \mathrm{mmHg}$, PP 15: peritoneal pressure $15 \mathrm{mmHg}, \mathrm{D} 20$ : head-down $20^{\circ}, \mathrm{D} 10$ : head-down $10^{\circ}$, U20: headup 20, U10: head-up $10^{\circ}$. Values are express as mean \pm SD. $* \mathrm{P}<0.05$ compared with neutral position, ${ }^{\dagger} \mathrm{P}<0.05$ compared with PP $10,{ }^{\dagger} \mathrm{P}$ $<0.05$ compared with PI. 


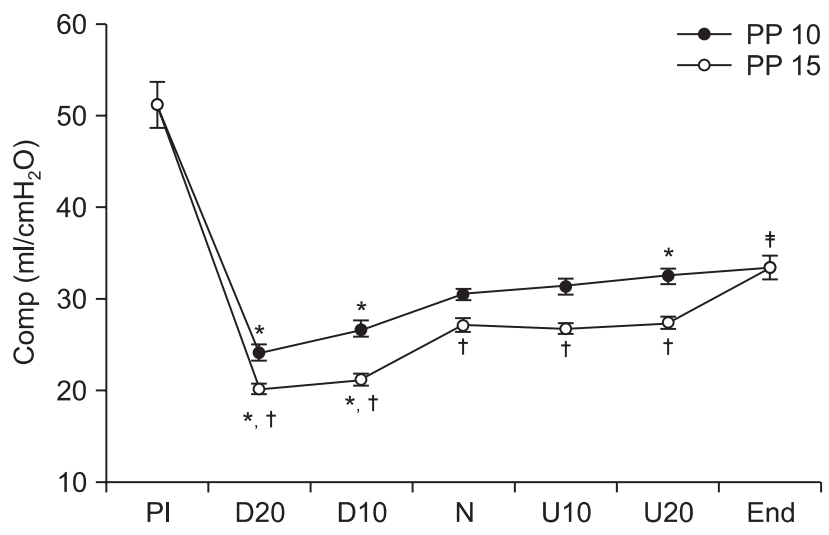

Fig. 3. These are changes in lung compliance (Comp) during laparoscopic assisted colectomy. Comp level during the headdown position is higher than when in the neutral position (N). All parameters at PP 15 are higher than PP 10. Comp after deflation of pneumoperitoneum (End) is higher than Comp before insufflation (PI). PP 10: peritoneal pressure $10 \mathrm{mmHg}$, PP 15: peritoneal pressure $15 \mathrm{mmHg}$, D20: head-down $20^{\circ}$, D10: head-down $10^{\circ}$, U20: headup 20, U10: head-up $10^{\circ}$. Values are express as mean \pm SD. $* \mathrm{P}<0.05$ compared with neutral position, ${ }^{\dagger} \mathrm{P}<0.05$ compared with $\mathrm{PP} 10,{ }^{\ddagger} \mathrm{P}$ $<0.05$ compared with PI.

significant differences in U10 and U15 compared to N. When comparing intraperitoneal pressure of $15 \mathrm{mmHg}$ in D10 with intraperitoneal pressure of $10 \mathrm{mmHg}$ in D20, the Ppeak and Pplat of D10 intraperitoneal pressure $15 \mathrm{mmHg}$ were 30.4 $\mathrm{cmH}_{2} \mathrm{O}$ and $27.6 \mathrm{cmH}_{2} \mathrm{O}$ respectively, which were higher than the Ppeak and Pplat of $28.4 \mathrm{cmH}_{2} \mathrm{O}$ and $25.6 \mathrm{cmH}_{2} \mathrm{O}$ of D20 intraperitoneal pressure $10 \mathrm{mmHg}$, but this difference was not statistically significant. Ppeak and Pplat after removing the pneumoperitoneum both increased significantly compared to $\mathrm{PI}(\mathrm{P}<0.05)$ (Fig. 1 and 2).

Comp significantly decreased in D10 and D20 at both intraperitoneal pressures compared to $\mathrm{N}(\mathrm{P}<0.05)$. At an intraperitoneal pressure of $10 \mathrm{mmHg} \mathrm{U} 20$, Comp significantly increased from $30.6 \mathrm{ml} / \mathrm{cmH}_{2} \mathrm{O}$ to $32.6 \mathrm{ml} / \mathrm{cmH}_{2} \mathrm{O}$ compared to $\mathrm{N}(\mathrm{P}=0.002)$, but at an intraperitoneal pressure of $15 \mathrm{mmHg}$, Comp was $27.4 \mathrm{ml} / \mathrm{cmH}_{2} \mathrm{O}$, which showed no significant difference from the $\mathrm{N}$ value of $27.2 \mathrm{ml} / \mathrm{cmH}_{2} \mathrm{O}(\mathrm{P}=0.989)$. In the pneumoperitoneum state, Comp was significantly higher at an intraperitoneal pressure of $10 \mathrm{cmH}_{2} \mathrm{O}$ than at a pressure of 15 $\mathrm{cmH}_{2} \mathrm{O}$ in all positions $(\mathrm{P}<0.05)$. Compared to $\mathrm{PI}$, Comp had significantly decreased at End $(\mathrm{P}<0.05)$ (Fig. 3).

Raw was $15.8 \mathrm{cmH}_{2} \mathrm{O} / \mathrm{L} / \mathrm{sec}$ when the intraperitoneal pressure was $10 \mathrm{cmH}_{2} \mathrm{O}$ in D20, which was lower than the $16.2 \mathrm{cmH}_{2} \mathrm{O} / \mathrm{L} /$ sec measured at intraperitoneal pressure $15 \mathrm{cmH}_{2} \mathrm{O}$ in D20. At pressures of $10 \mathrm{cmH}_{2} \mathrm{O}$ and $15 \mathrm{cmH}_{2} \mathrm{O}$, the Raw value in $\mathrm{D} 10$ and D20 significantly increased compared to $\mathrm{N}(\mathrm{P}<0.05)$, while there was no significant difference in the head up positions. Raw after removing pneumoperitoneum significantly increased compared

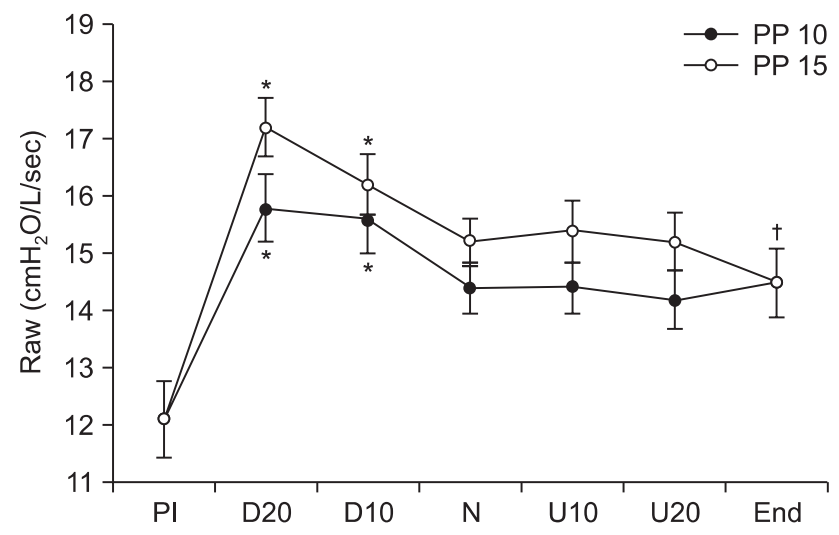

Fig. 4. These are changes in airway resistance (Raw) during laparoscopic assisted colectomy. Raw during head-down position (D20, $\mathrm{D} 10)$ is higher than neutral position (N). All parameters at PP 15 are higher than at PP 10. Raw after deflation of pneumoperitoneum (End) is higher than Raw before insufflation (PI). PP 10: peritoneal pressure $10 \mathrm{mmHg}$, PP 15: peritoneal pressure $15 \mathrm{mmHg}, \mathrm{D} 20$ : head-down 20, D10: head-down $10^{\circ}$, U20: head-up $20^{\circ}$, U10: headup $10^{\circ}$. Values are express as mean $\pm \mathrm{SD}$. $* \mathrm{P}<0.05$ compared with neutral position, ${ }^{\dagger} \mathrm{P}<0.05$ compared with PI.

to PI, and there were no significant differences in Raw between the two intraperitoneal pressures (Fig. 4).

\section{Discussion}

In this study, in the head down position when intraperitoneal pressure was increased from $10 \mathrm{mmHg}$ to $15 \mathrm{mmHg}$, the Ppeak, Pplat, and Raw increased and the Comp decreased. In the head up position the respiratory mechanical changes appeared differently according to intraperitoneal pressure and to inclination.

The Comp and Raw measured at an intraperitoneal pressure of $10 \mathrm{mmHg}$ in D20 were $24.2 \mathrm{ml} / \mathrm{cmH}_{2} \mathrm{O}$ and $15.8 \mathrm{cmH}_{2} \mathrm{O} / \mathrm{L} /$ sec, and compared to the values of $21.2 \mathrm{ml} / \mathrm{cmH}_{2} \mathrm{O}$ and 16.2 $\mathrm{cmH}_{2} \mathrm{O} / \mathrm{L} / \mathrm{sec}$ measured at $15 \mathrm{mmHg}$ in D10, Comp was higher and Raw was lower, although the difference was not statistically significant. At an intraperitoneal pressure of $10 \mathrm{mmHg}$ in U20, the Comp significantly increased from 30.6 to $32.6 \mathrm{ml} / \mathrm{cmH}_{2} \mathrm{O}$ compared to $\mathrm{N}$, while at an intraperitoneal pressure of 15 $\mathrm{mmHg}$ in U10, Comp did not increase compared to N. These results suggest that an increase in intraperitoneal pressure has a greater effect on respiratory mechanics than does position change. Hence, in cases where intraperitoneal pressure is increased and the head down position is utilized to obtain surgical space, lowering intraperitoneal pressure and changing position more is better and important in the respiratory management of patients during and after surgery.

When changing to the head down position from the supine 
position, diaphragm muscle paralysis occurs due to muscle relaxants administered to patients receiving general anesthesia. In addition, the intraperitoneal organs and intrathoracic blood volume compress the lungs due to gravity, which reduces Comp of the lungs and decreases functional residual volume. Hence, in patients receiving positive ventilation under general anesthesia, merely changing the position can cause changes in respiratory mechanics. However, in the head up position, changes in respiratory mechanics appear differently according to intraperitoneal pressure and degree of inclination. In the head up position, as intraperitoneal pressure increases, the diaphragm is pushed up due to pneumoperitoneum, but the intraperitoneal organs fall down due to gravity so the Comp of the lungs increases [7]. In this study, when compared with $\mathrm{N}$, head up positions of $10^{\circ}$ and $20^{\circ}$ had increased Comp at an intraperitoneal pressure of $10 \mathrm{mmHg}$ but Comp did not increase at intraperitoneal pressure of $15 \mathrm{mmHg}$. This is considered to be due to the intraperitoneal pressure of $15 \mathrm{mmHg}$ sufficient to push the diaphragm up in the head up position, while an intraperitoneal pressure of $10 \mathrm{mmHg}$ is not sufficient.

It is essential in laparoscopic surgery to create space in the intraperitoneum for the instruments to move, and to create this space carbon dioxide is injected to cause pneumoperitoneum, which leads to increased intraperitoneal pressure. The increased intraperitoneal pressure from the pneumoperitoneum pushes the diaphragm toward the head, causing a decrease in lung volume. As a result, laparoscopic surgery has a more frequent occurrence of compression atelectasis than laparotomy [4].

Pneumoperitoneum reduces lung compliance, and blood absorbance of carbon dioxide increases arterial carbon dioxide tension. Therefore, due to increase in minute ventilation, the Ppeak and Pplat increase in a state of reduced lung compliance state $[7,8]$. In an animal study conducted on dogs by Greenfied et al. [3], when Ppeak was $30 \mathrm{mmHg}$ or more, increased respiratory complications such as pulmonary edema and atelectasis were reported. Additionally, Fernández-Pérez et al. [9] reported that when patients are exposed to high Ppeak during surgery, there is a higher frequency of acute lung injury occurring after surgery.

In the current study, the laparoscopic colectomy continued for $2 \mathrm{~h}$ or more in the head down position under an intraperitoneal pressure of $15 \mathrm{mmHg}$, and when sufficient minute ventilation was provided, 12 out of 30 patients had a Ppeak of 30 or more. Our study did not have a control group, so the occurrence rate of respiratory complications after surgery could not be compared, but reducing tidal volume to reduce Ppeak during surgery can cause hypoventilation along with a risk of hypoxemia and hypercarbia. It is also anticipated that an increase in Ppeak and Pplat during and after surgery can lead to respiratory complications such as pulmonary edema or atelectasis and physiological changes in the lungs related to acute lung injury.
Hence when performing long hours of laparoscopic surgery, the surgeon and anesthesiologist need to reduce the possibility of hypoxemia and hypercarbia while lowering the values of Ppeak and Pplat.

The patients in our study had no pulmonary disease, were not obese, and were ASA level 1 or 2, so the changes in respiratory mechanics during laparoscopic surgery have less clinical meaning. Changing positions and intraperitoneal pressure in patients who have existing pulmonary diseases or are morbidly obese can intensify respiratory mechanics changes, or cause lung functional damage after surgery [10]. Dumont et al. [11] reported that changes in respiratory mechanics from laparoscopic surgery were intensified in obese patients, and resulted a higher number of complications in these patients. Salihoglu et al. [8] reported that when a patient group with chronic obstructive pulmonary disease was compared to a normal control group, the pneumoperitoneum caused a decrease in arterial oxygen tension and an increase in arterial carbon dioxide tension, and the head down position made these changes worse. Therefore when performing laparoscopic surgery in patients with existing pulmonary disease or morbid obesity, it is considered essential to reduce intraperitoneal pressure within the range that will not disturb the surgery. In addition, when performing laparoscopic surgery, it is better to insert carbon dioxide to an appropriate pressure after checking respiratory changes during surgery rather than injecting the same pressure en bloc, for safe and appropriate respiratory management in the perioperative period.

Limitations of this research include a lack of investigation regarding the field of vision and accessibility for each pressure and position, considering that increasing the intraperitoneal pressure and utilizing the head down position were meant to secure operative space and vision for the surgeon. Second, changes in respiratory mechanics were measured for a single group, so there could be no comparison regarding the frequency of respiratory complications after surgery. Third, there was no measurement of arterial oxygen and carbon dioxide tension for each position and intraperitoneal pressure. This was not performed due to the time to equilibrium which may have had an impact on operating time.

\section{Acknowledgments}

This research was supported by Basic Science Research Program through the National Research Foundation of Korea (NRF) funded by the Ministry of Education, Science and Technology (2012R1A1A1003700).

\section{References}

1. Lacy AM, García-Valdecasas JC, Delgado S, Castells A, Taurá P, Piqué 
JM, et al. Laparoscopy-assisted colectomy versus open colectomy for treatment of non-metastatic colon cancer: a randomized trial. Lancet 2002; 359: 2224-9.

2. Plocek MD, Geisler DP, Glennon EJ, Kondylis P, Reilly JC. Laparoscopic colorectal surgery in the complicated patient. Am J Surg 2005; 190: 882-5.

3. Greenfied LJ, Ebert PA, Benson DW. Effect of positive pressure ventilaton on surface tension properties of lung extracts. Anesthesiology 1964; 25: 312-6.

4. Joshi GP. Complications of laparoscopy. Anesthesiol Clin North America 2001; 19: 89-105.

5. Shapiro BA, Harrison RA, Kacmarek RM, Cane RD. Clinical application of respiratory care. 3rd ed. Philadephia, Springer publishing company. 1985, pp 362-7.

6. Rauh R, Hemmerling TM, Rist M, Jacobi KE. Influence of pneumoperitoneum and patient positioning on respiratory system compliance. J Clin Anesth 2001; 13: 361-5.

7. Mäkinen MT, Yli-Hankala A. Respiratory compliance during laparo- scopic hiatal and inguinal hernia repair. Can J Anaesth 1998; 45: 86570.

8. Salihoglu Z, Demiroluk S, Baca B, Ayan F, Kara H. Effects of pneumoperitoneum and positioning on respiratory mechanics in chronic obstructive pulmonary disease patients during Nissen fundoplication. Surg Laparosc Endosc Percutan Tech 2008; 18: 437-40.

9. Fernández-Pérez ER, Sprung J, Afessa B, Warner DO, Vachon CM, Schroeder DR, et al. Intraoperative ventilator settings and acute lung injury after elective surgery: a nested case control study. Thorax 2009; 64: 121-7.

10. Takahata O, Kunisawa T, Nagashima M, Mamiya K, Sakurai K, Fujita $\mathrm{S}$, et al. Effect of age on pulmonary gas exchange during laparoscopy in the Trendelenburg lithotomy position. Acta Anaesthesiol Scand 2007; 51: 687-92.

11. Dumont L, Mattys M, Mardirosoff C, Vervloesem N, Alle JL, Massaut J. Changes in pulmonary mechanics during laparoscopic gastroplasty in morbidly obese patients. Acta Anaesthesiol Scand 1997; 41: 408-13. 